\title{
Dynamic Response of a Vehicle-Bridge Expansion Joint Coupled System
}

\author{
Lu Zhang $\mathbb{D}^{1,2}$ Shaohua Wang, ${ }^{2,3}$ and Bing $\mathrm{Li} \mathbb{D}^{4}$ \\ ${ }^{1}$ Automation Research Institute Co., Ltd. of China South Industries Group Corporation, Mianyang 621022, China \\ ${ }^{2}$ School of Mechanical Engineering, Southwest Jiaotong University, Chengdu 610031, China \\ ${ }^{3}$ Technology and Equipment of Rail Transit Operation and Maintenance Key Laboratory of Sichuan Province, \\ Mianyang 610031, China \\ ${ }^{4}$ School of Mechanical Engineering, North China University of Water Resources and Electric Power, Zhengzhou 450045, China
}

Correspondence should be addressed to Lu Zhang; jd_zhanglu@163.com and Bing Li; libing19881007@163.com

Received 17 June 2021; Revised 7 November 2021; Accepted 22 December 2021; Published 11 January 2022

Academic Editor: Junhong Park

Copyright (C) $2022 \mathrm{Lu}$ Zhang et al. This is an open access article distributed under the Creative Commons Attribution License, which permits unrestricted use, distribution, and reproduction in any medium, provided the original work is properly cited.

\begin{abstract}
The paper investigates the dynamic vibration property of the vehicle-bridge expansion joint coupled system with the proposed model. The dynamic response of the expansion joint under the action of the vehicle is the key factor affecting the life of the expansion joint. The changes of contact state and tire geometric characteristics were frequently left aside in the past to simplify the tire model. This is because the contact between tire and expansion joint is a very complex process. But this will seriously underestimate the impact effect of the vehicle on the expansion joint. In this paper, a dynamic mathematical model of the 2-axle vehicle-modular bridge expansion joint (MBEJ) coupled system is established by introducing a flexible roller tire model. The influence of tread rigid displacement and change in the tire contact patch length are considered in the dynamic model. Based on this model, the characteristics of the dynamic tire load and the center beam vibration displacement in the coupled system are obtained by simulation. The results show that the maximum dynamic tire load of the vehicle occurs at the end of the bridge deck behind the MBEJ, so local structure reinforcement needs to be considered. The interaction between the front and rear wheels of the 2 -axle vehicle can be ignored. The vehicle position, vehicle velocity, gap width, and spring stiffness of the center beam bearing have significant effects on the impact factors of tire load and center beam vibration displacement. The impact factor of tire load may exceed the recommended values of Chinese and European bridge codes. These should be taken seriously.
\end{abstract}

\section{Introduction}

Bridge Expansion joints are exposed to the environment of high humidity, large temperature difference, and strong vibration for a long time, which are potential weak spots. The performance of the modular bridge expansion joint (MBEJ) based on the static performance indices cannot meet the requirements of bridge heavy load and heavy traffic flow, and its life span is greatly reduced $[1,2]$. Therefore, it is of great significance for the design and maintenance of expansion joints and bridges to study the dynamic characteristics of MBEJs under passing vehicles.

The vibrations of MBEJs include vertical vibration and horizontal vibration. At present, there are few analyses on the dynamic performance of expansion joints. The impact effect of MBEJ vertical vibration is the main reason for the failure of center beam weld [3]. The horizontal vibration mainly affects the safety of the connection between the bridge deck and the MBEJ and the service life of the sliding bearing [4-6]. The research by Shun et al. [7] on the interaction between vertical vibration and horizontal vibration of MBEJs showed that the vibrations in two directions are independent of each other, so they can be studied separately. At present, there are few analyses on the vertical vibration performance of expansion joints. A study by Steenbergen [8] on the impact factor of an MBEJ showed that the impact factor of expansion joints can be as high as 1.7, which is much higher than those prescribed in the current design 
code. Ancich et al. [9] completed the experimental modal analysis and operational response shape studies on an MBEJ installed in the Anzac Bridge to indicate that the dynamic range factor can be reduced by introducing additional damping. Li [10] and Yan [11] analyzed the influence of vehicle velocity, joint gap width, and spring stiffness of the center beam bearings on the vertical dynamic characteristics of an MBEJ by using sine loads to simulate the action of vehicle. The MBEJ is often regarded as an independent system to study its dynamic property, which can simplify the model to a certain extent. The interaction between the vehicle and the MBEJ is not considered in this type of model. This will lead to too large deviations in the solution results of this type of model in the high-frequency vibration region. Therefore, the coupled effect between vehicles and MBEJ needs to be considered [12].

To make the simulation results more accurate, $\mathrm{Wu}$ et al. [13] established a numerical model of vehicle-steel boxgirder based on rigid wheel model to verify that the existence of expansion joints significantly increases the impact effect of vehicles on the bridge. Sun and Zhang [14] applied a single-DOF vehicle model to the finite element model of a vehicle-MBEJ coupled system to analyze the vibration characteristics of the MBEJ. The results showed that the vehicle loads will cause the significant dynamic response of the MBEJ. Deng et al. [15] proved that the damage condition of expansion joints has a significant impact on the bridge deck by establishing a vehicle-bridge coupled model in which the expansion joint was defined as a road-surface profile according to the damage degree of the expansion joint. Friedl and Mangerig [16] and Mangerig and Friedl [17] proposed a vehicle-expansion joint coupled system model based on a plane tire model to analyze the dynamic response of the coupled system when the vehicle passed through the expansion joint. The model considered the nonuniform pressure distribution in the contact area between the tire and the center beam. Ding et al. [18, 19] proposed a distributed spring-damper element for dynamic simulation of vehicles passing through expansion joints, in which the contact patch between the tire and the expansion joint was considered. However, the existing mathematical models do not consider the change in the tire contact patch length, which will cause the impact of tire load in the calculation process to be overestimated, resulting in the limitations of the use of models. Therefore, it is necessary to establish a more precise model for the contact relationship between the tire and the expansion joint in the coupled system model.

In this paper, a dynamic mathematical model of the vehicle-MBEJ coupled system by introducing a flexible roller tire model is proposed. This model considers the excitation characteristics of the tire load. The validity of this model has been verified in our published paper [20]. Based on the dynamic mathematical model, the vibration characteristics of the coupled system is simulated, and the influence of the parameters on the impact factors of the tire load and the center beam are analyzed.

\section{Dynamic Mathematical Model}

Figure 1 shows an example of a vehicle-MBEJ coupled system. $x$ is the width direction of the bridge deck, $y$ is the vertical upward direction, $z$ is the axial direction of the bridge deck, and the subscripts $\mathrm{C}, \mathrm{Z}$, and $\mathrm{H}$ denote the gravity center of the vehicle body, center beam, and crossbeam, respectively. The MBEJ in the model consists of 5 center beams and 10 crossbeams. Center beams are perpendicular to the driving lane, while crossbeams are laid parallel to the driving lane under the center beams. Center beams and the crossbeams are connected by sliding bearings, and crossbeams and the bridge are connected by bearings installed in displacement box. A 2-axle heavy vehicle is taken as an example.

2.1. The Vehicle Dynamic Model. The 7-DOF vehicle model [21] is proved to be efficient to simulate 2 -axle heavy vehicle. The 7-DOF vehicle models are the vertical displacement, the roll and pitch angles of the vehicle body, and the four vertical displacements of the wheels. Based on the D'Alembert principle, the differential equation of the vehicle system is expressed as

$$
\mathbf{M}_{V} \mathbf{A}_{V}+\mathbf{C}_{V} \mathbf{V}_{V}+\mathbf{K}_{V} \mathbf{X}_{V}=\mathbf{R}_{V},
$$

where $\mathbf{M}_{V}, \mathbf{C}_{V}$, and $\mathbf{K}_{V}$ are the mass matrix, stiffness matrix, and damping matrix of the vehicle system, respectively, $\mathbf{A}_{V}$, $\mathbf{V}_{V}$, and $\mathbf{X}_{V}$ are the acceleration vector, velocity vector, and displacement vector of the vehicle system, respectively, and $\mathbf{R}_{V}$ is the force vector of the vehicle system. The specific explanations of these parameters can be found in [21].

The parameters of the 2-axle heavy vehicle adopted in simulation are listed in Table 1.

2.2. The MBEJ Dynamic Model. The center beam and crossbeam are slender beams, of which the cross-section dimensions are far less than the lengthwise dimensions. Therefore, the vibration equations of the center beam and crossbeam can be obtained by Euler beam theory, and the calculation accuracy is proved to be acceptable [11]. Denoting the vertical displacement of the $i$ th center beam as $y_{\mathrm{Zi}}(x, t)$, the vibration equation is given as follows.

$$
E_{Z} I_{Z} \frac{\partial^{4} y_{Z i}(x, t)}{\partial_{x}^{4}}+m_{Z} \frac{\partial^{2} y_{Z i}(x, t)}{\partial t^{2}}=-\sum_{j=1}^{N J} F_{H j i}(t) \delta\left(x-x_{j}\right)-\sum_{k=1}^{N K}\left[F_{T L k i}(t) \delta\left(x-x_{L k}\right)+F_{T R k i}(t) \delta\left(x-x_{R k}\right)\right],
$$




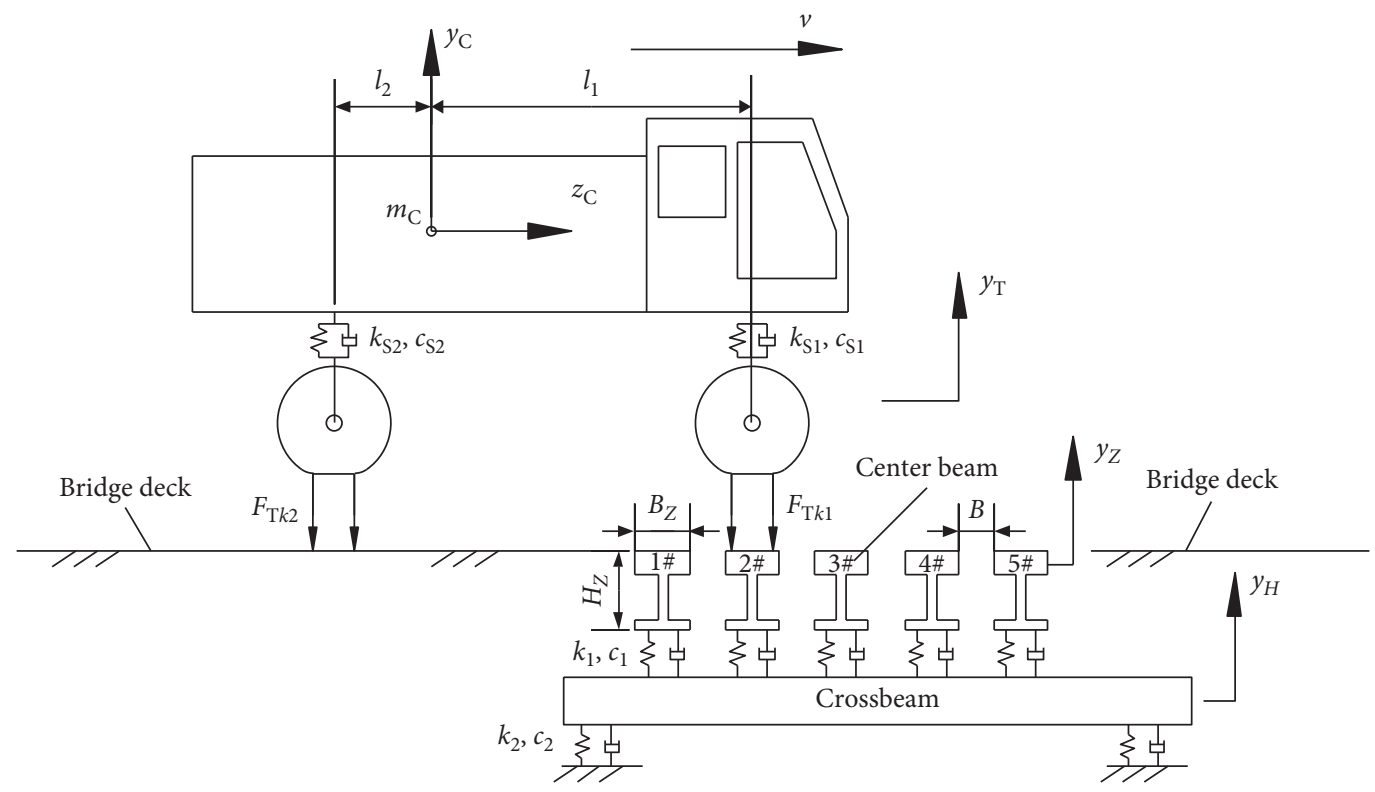

FIGURE 1: Force analysis of the 2-axle vehicle-expansion joint coupled system.

TABle 1: Parameters of the 2-axle heavy vehicle model.

\begin{tabular}{lccc}
\hline Parameter & Value & Parameter & Value \\
\hline Mass of vehicle body, $m_{\mathrm{C}}(\mathrm{kg})$ & 16000 & Spring stiffness of front axle tire, $k_{\mathrm{T} 1}(\mathrm{kN} / \mathrm{m})$ & 1190 \\
Pitching moment of inertia of truck body, $J_{\mathrm{C} x}\left(\mathrm{~kg} \cdot \mathrm{m}^{2}\right)$ & 78904 & Spring stiffness of rear axle tire, $k_{\mathrm{T} 2}(\mathrm{kN} / \mathrm{m})$ & 2380 \\
Rolling moment of inertia of truck body, $J_{\mathrm{C} z}\left(\mathrm{~kg} \cdot \mathrm{m}^{2}\right)$ & 4560 & Damping coefficient of front axle tire, $c_{\mathrm{T} 1}(\mathrm{kN} \cdot \mathrm{s} / \mathrm{m})$ & 3.5 \\
Mass of front axle suspension, $m_{\mathrm{T} 1}(\mathrm{~kg})$ & 200 & Damping coefficient of rear axle tire, $c_{\mathrm{T} 2}(\mathrm{kN} \cdot \mathrm{s} / \mathrm{m})$ & 7 \\
Mass of rear axle suspension, $m_{\mathrm{T} 2}(\mathrm{~kg})$ & 400 & Distance between front axle and gravity center, $l_{1}(\mathrm{~m})$ & 3.92 \\
Spring stiffness of front axle suspension, $k_{\mathrm{S} 1}(\mathrm{kN} / \mathrm{m})$ & 210.67 & Distance between front rear and gravity center, $l_{2}(\mathrm{~m}) \quad 1.68$ \\
Spring stiffness of rear axle suspension, $k_{\mathrm{S} 2}(\mathrm{kN} / \mathrm{m})$ & 942.64 & Wheel center distance of front axle, $2 b_{1}(\mathrm{~m})$ & 1.88 \\
Damping coefficient of front axle suspension, $c_{\mathrm{S} 1}(\mathrm{kN} \cdot \mathrm{s} / \mathrm{m})$ & 14.63 & Wheel center distance of rear axle, 2b $2 b_{2}(\mathrm{~m})$ & 1.86 \\
Damping coefficient of rear axle suspension, $c_{\mathrm{S} 2}(\mathrm{kN} \cdot \mathrm{s} / \mathrm{m})$ & 10 & & \\
\hline
\end{tabular}

where $E_{Z}$ is the elasticity modulus of the center beam, $I_{Z}$ is the section inertia of the center beam, $\mathrm{F}_{\mathrm{H} j i}$ is the supporting force from the $j$ th crossbeam to the $i$ th center beam, $F_{\mathrm{TL} k i}(t)$, $F_{\mathrm{TR} k i}(t)$ are the contact forces between the wheels of the $k \mathrm{th}$ axle and the $i$ th center beam with subscripts TL and TR representing the left and right wheels of the vehicle, $N J$ is the total number of crossbeams, $x_{j}$ is the $x$ coordinate of the $j$ th crossbeam central axis, $N K$ is the total number of axles, and $x_{\mathrm{L} k}, x_{\mathrm{R} k}$ are the $x$ coordinates of the left and right wheels on the $k^{\text {th }}$ axle. $\delta$ is the Kirchhoff function. The supporting force $\mathrm{F}_{\mathrm{H} j i}(t)$ can be described as

$$
F_{H j i}(t) \delta\left(x-x_{j}\right)=k_{1}\left[y_{Z j}\left(x_{j}, t\right)-y_{H j}\left(z_{i}, t\right)\right]+c_{1}\left[\dot{y}_{Z j}\left(x_{j}, t\right)-\dot{y}_{H j}\left(z_{i}, t\right)\right],
$$

where $k_{1}, c_{1}$ are the spring stiffness and damping coefficient of the center beam bearing, $y_{\mathrm{H} j}\left(z_{i}, t\right)$ is the displacement of the $j$ th crossbeam at the coordinate $z_{i}$, and $z_{i}$ is the $z$ coordinate of the $i$ th center beam central axis.
Similarly, the vertical displacement of $j$ th crossbeam $y_{\mathrm{H} j}(z, t)$ is expressed as

$$
E_{H} I_{H} \frac{\partial^{4} y_{H j}(z, t)}{\partial z^{4}}+m_{H} \frac{\partial^{2} y_{H j}(z, t)}{\partial t^{2}}=-\sum_{i=1}^{N I} F_{I i j}(t) \delta\left(z-z_{i}\right)-\sum_{h=1}^{2} F_{0 h j}(t) \delta\left(z-z_{0 h}\right)
$$


where $E_{H}$ is the elasticity modulus of the crossbeam, NI is the total number of center beams, $\mathrm{F}_{\mathrm{I} i j}(t)$ is the supporting force from the $i$ th center beam to the $j$ th crossbeam, $\mathrm{F}_{0 h j}(t)$ is the supporting force from bridge deck to the $j$ th crossbeam, $h$ is the bearing in the displacement box at the end of the crossbeam, and $z_{0 h}$ is the $z$ coordinate of the bearing. The supporting force $F_{\mathrm{I} i j}(t)$ can be described as

$$
F_{I i j}(t) \delta\left(z-z_{i}\right)=-k_{1}\left[y_{Z i}\left(x_{j}, t\right)-y_{H j}\left(z_{i}, t\right)\right]-c_{1}\left[\dot{y}_{Z i}\left(x_{j}, t\right)-\dot{y}_{H j}\left(z_{i}, t\right)\right] .
$$

For the supporting forces received by the crossbeam, we can obtain

$$
F_{0 h j}(t) \delta\left(z-z_{0 h}\right)=k_{2} y_{H j}\left(z_{0 h}, t\right)+c_{2} \dot{y}_{H j}\left(z_{o h}, t\right)
$$

where $k_{2}, c_{2}$ are the spring stiffness and damping coefficient of the crossbeam bearing.

The structural parameters of the MBEJ adopted in simulation are listed in Table 2.

2.3. Contact Relationship between the Tire and the MBEJ. Due to the discontinuity of the top surface of the MBEJ, it is necessary to consider the local separation between the bottom of the tire and the MBEJ at the gap [19]. In order to accurately represent the contact relationship between the tire and the MBEJ, a tire model with the profile function of MBEJ's top surfaces added to the revised flexible roller contact tire model $[22,23]$ is proposed [20], as shown in Figure 2. The compression deformations of the contact points between the $k$ th tire and the MBEJ in the model are expressed as

$$
y\left(z_{k}, z_{k}^{\prime}\right)= \begin{cases}y_{Z i}\left(x_{k}, t\right)+y_{0}\left(z_{k}+z_{k}^{\prime}\right)+\sqrt{r_{0}^{2}-z_{k}^{\prime 2}}-r_{0}-y_{T k}\left(z_{k}\right)-y_{T s k}, & \Delta y>0 \\ 0, & \Delta y \leq 0\end{cases}
$$

where $y_{0}\left(z_{k}+z_{k}^{\prime}\right)$ is the profile function of MBEJ's top surfaces, $z_{k}$ is the $z$-direction displacement of the $k$ th wheel axis, $z_{k}^{\prime}$ is the local $z$ coordinate in the contact patch of the $k$ th tire, $-r_{0} \leq z_{k}^{\prime} \leq r_{0}, r_{0}$ is the tire free radius, and $y_{\mathrm{Ts} k}$ is the static load-deflection of the $k$ th tire. The profile function $y_{0}\left(z_{k}+z_{k}^{\prime}\right)$ is given as

$$
y_{0}\left(z_{k}+z_{k}^{\prime}\right)= \begin{cases}0, & z_{i}-\frac{B_{Z}}{2} \leq z_{k}+z_{k}^{\prime} \leq z_{i}+\frac{B_{Z}}{2}, \\ -H_{Z} z_{i}-\frac{B_{Z}}{2}-B<z_{k}+z_{k}^{\prime}<z_{i}-\frac{B_{Z}}{2}, & \text { or } z_{i}+\frac{B_{Z}}{2}<z_{k}+z_{k}^{\prime}<z_{i}+\frac{B_{Z}}{2}+B,\end{cases}
$$

where $B_{\mathrm{Z}}, H_{\mathrm{Z}}$ are the width of the center beam top surface and the height of the center beam, respectively, and $B$ is the gap width.
Then, the contact force between the $k$ th tire and the $\operatorname{MBEJ} F_{\mathrm{T} k}(t)$ and the contact force between the $k$ th tire and the $i$ th center beam are given as

$$
\begin{aligned}
F_{T k}(t) & =\sum_{i=1}^{N I} F_{T k i}(t), \\
F_{T k i}(t) & =\int_{a_{k i}}\left[k_{T k}\left(z_{k}^{\prime}\right) \Delta y\left(z_{k}, z_{k}^{\prime}, t\right)+c_{T k}\left(z_{k}^{\prime}\right) \Delta \dot{y}\left(z_{k}, z_{k}^{\prime}, t\right)\right] d z_{k}^{\prime},
\end{aligned}
$$


TABLE 2: Structural parameters of the MBEJ model.

\begin{tabular}{lccc}
\hline Parameter & Value & Parameter & Value \\
\hline$E_{\mathrm{Z}}, E_{\mathrm{H}}(\mathrm{GPa})$ & 205 & $c_{1}, c_{2}(\mathrm{~N} \cdot \mathrm{s} / \mathrm{mm})$ & 5 \\
$m_{\mathrm{Z}}(\mathrm{kg} / \mathrm{m})$ & 49.33 & $B(\mathrm{~mm})$ & $0-80$ \\
$m_{\mathrm{H}}(\mathrm{kg} / \mathrm{m})$ & 315.9 & $B_{\mathrm{F}}(\mathrm{mm})$ & 90 \\
$I_{\mathrm{Z}}\left(\mathrm{m}^{4}\right)$ & $1.24 \times 10^{-5}$ & $H_{\mathrm{Z}}(\mathrm{mm})$ & 130 \\
$I_{\mathrm{H}}(\mathrm{m} 4)$ & $2.46 \times 10^{-4}$ & $L_{\mathrm{H}}(\mathrm{m})$ & 4.2 \\
$k_{2}(\mathrm{kN} / \mathrm{m})$ & 60 & $L_{\mathrm{Z}}(\mathrm{m})$ & 10.2 \\
\hline
\end{tabular}

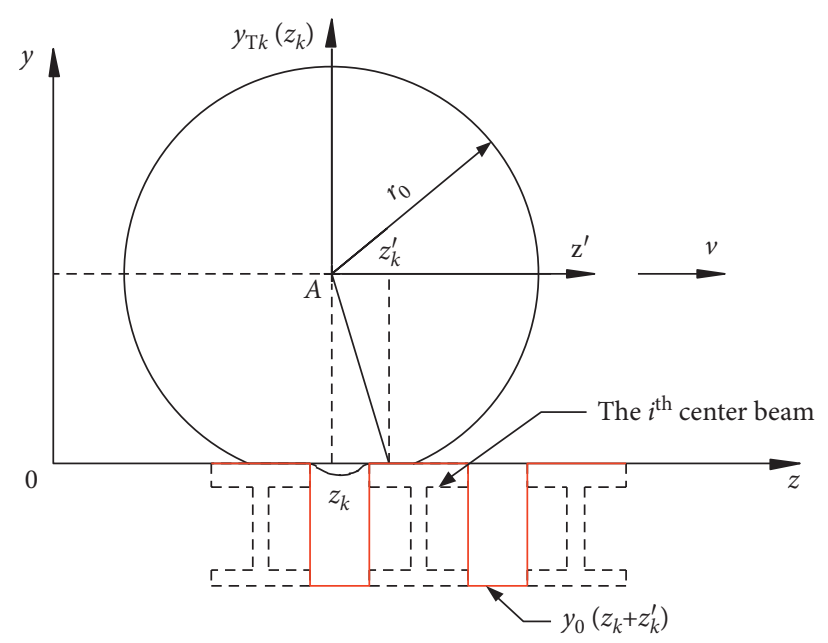

Figure 2: The contact relationship between the tire and the MBEJ.

where $k_{T k}\left(z_{k}^{\prime}\right), c_{T k}\left(z_{k}^{\prime}\right)$ are spring stiffness and damping coefficient of the $k$ th tire vertical distributing, and $a_{k i}$ is the contact patch length between the $k$ th tire and the $i$ th center beam. The tire vertical distributing spring stiffness $k_{\mathrm{T} k}$ and damping coefficient $c_{T k}$ can be obtained by a simplified formula [24], expressed as

$$
\begin{aligned}
& k_{T k}\left(z_{k}^{\prime}\right)=\frac{k_{T k}}{2 a_{k}}, \\
& c_{T k}\left(z_{k}^{\prime}\right)=\frac{c_{T k}}{2 a_{k}},
\end{aligned}
$$

where $a_{k}$ is the half of contact patch length between the $k$ th tire and contact surface. The $a_{k}$ can be defined as

$$
a_{k}=\sqrt{r_{0}^{2}-f^{2}}
$$

where $f$ is the load-deflection of the tire tread.

When radial tire is under load, the belt will have rigid displacement [25]; i.e., the wheel axis deviates from the tire center. Let $f_{\mathrm{b}}$ denote the rigid displacement, the tire loaddeflection of the wheel axis $\Delta y$ can be expressed as

$$
\Delta y=f_{b}+f=r_{0}-r,
$$

where $r$ is the tire rolling radius.

2.4. Numerical Integration Method. With regard to the vehicle-MBEJ coupled system, the dynamic equation can be described as

$$
\left[\begin{array}{cc}
\mathbf{M}_{V} & 0 \\
0 & \mathbf{M}_{E}
\end{array}\right]\left\{\begin{array}{l}
\mathbf{A}_{V} \\
\mathbf{A}_{E}
\end{array}\right\}+\left[\begin{array}{cc}
\mathbf{C}_{V} & \mathbf{C}_{V E} \\
\mathbf{C}_{E V} & \mathbf{C}_{E}
\end{array}\right]\left\{\begin{array}{l}
\mathbf{V}_{V} \\
\mathbf{V}_{E}
\end{array}\right\}++\left[\begin{array}{cc}
\mathbf{K}_{V} & \mathbf{K}_{V E} \\
\mathbf{K}_{E V} & \mathbf{K}_{E}
\end{array}\right]\left\{\begin{array}{l}
\mathbf{X}_{V} \\
\mathbf{X}_{E}
\end{array}\right\}=\left\{\begin{array}{l}
\mathbf{R}_{V} \\
\mathbf{R}_{E}
\end{array}\right\},
$$

where $\mathbf{M}, \mathbf{C}$, and $\mathbf{K}$ are the mass matrix, damping matrix, and stiffness matrix of the system; the subscripts $V$ and $E$ represent the vehicle system and expansion joint system; $\mathbf{X}, \mathbf{V}$, and $\mathbf{A}$ represent the generalized displacement, velocity, and acceleration matrix; $R$ is the generalized force matrix.
The simple fast explicit integration method [26] is used to solve (13). The initial conditions are listed as

$$
\left\{\begin{array}{l}
\mathbf{V}_{V}(0)=\mathbf{X}_{V}(0)=0 \\
\mathbf{V}_{E}(0)=\mathbf{X}_{E}(0)=0
\end{array}\right.
$$


A test of a four-axle vehicle passing an MBEJ has been completed to verify the accuracy of the vehicle-expansion joint coupled dynamics mathematical model. It shows that the dynamic model simulation results of the vertical velocity at the center beam test points match well with the test results. The deviations of the center beam maximum sinking displacement between the simulation results and the test results are less than $10 \%$. The test method and conclusions have been published in [21] in 2021.

\section{Impact Effect Evaluation}

In the study of a vibration system, the impact factor is often used to evaluate the impact effect $[8-10,14-20]$. In the vibration analysis of the vehicle-MBEJ coupled system, the impact of the dynamic tire loads and the impact of center beam vibration displacements are both very important. Therefore, two different impacts are adopted in this paper. In order to evaluate the impact effect of the dynamic tire loads, the dimensionless impact factor $\mu$ of the tire load is defined as [18-20]

$$
\mu=\frac{F_{T \max }-F_{T s}}{F_{T s}},
$$

where $F_{T \max }$ is the maximum tire load, and $F_{T s}$ is the static tire load.

Then, in order to evaluate the impact effect of the center beam vibration displacements, the dimensionless impact factor $I M$ of the center beam vibration displacements is defined as $[8-11,14-17]$

$$
I M=\frac{y_{\max }-y_{s}}{y_{s}},
$$

where $y_{\max }$ is the maximum displacement of the center beam due to the vehicle traveling at designated speed, $y_{\mathrm{s}}$ is the static displacement of the center beam due to a vehicle axle stopping directly above the center beam or the maximum displacement due to the vehicle traveling at low speed [9], and the velocity of $10 \mathrm{~km} / \mathrm{h}[10]$ is adopted for $y_{s}$ in the following study.

The impact factor $\mu$ can be applied to the design of the bridge local structure, and the impact factor IM can be applied to the design of expansion joints. In most cases, the values of these two factors are equal, but in the vehicleexpansion joint coupled system, we study them separately. The impact factors specified by some bridge design codes vary from country to country. The impact factors specified in Chinese bridge code [27] and European bridge code [28] are 0.3 , and that in American bridge code [29] is 0.75.

\section{Results and Analysis}

4.1. Dynamic Response of Vehicle. Before the simulation, we set the basic simulation conditions, where $v=80 \mathrm{~km} / \mathrm{h}$, $B=60 \mathrm{~mm}, k 1=60 \mathrm{kN} / \mathrm{m}$, and the center line of the left rear wheel contact patch passes through the midpoint of the center beam. The parameters in the following simulations are modified based on the basic conditions. The response of the vehicle wheels when the vehicle passes through the MBEJ is simulated by using the basic simulation conditions, as shown in Figures 3 and 4.

Figure 3 shows that both the vibration displacement waveforms and the vibration acceleration waveforms of the left and right tires are basically the same. Due to the large wheelbase, the interaction between the front and rear wheels can be ignored. Figure 4 shows that the dynamic loads of the left and right tires basically agree with each other, and the maximum loads of the front and rear wheels occur at the end of the bridge deck behind the MBEJ, which is consistent with the conclusion of Ding et al. [19]. The tire load impact factors $\mu$ s of the left front and rear wheels are 0.23 and 0.24 , respectively.

4.2. Dynamic Response of the MBEJ. Figure 5 shows that the vibration displacement response of the MBEJ center beams' midpoints during the vehicle crossing though an MBEJ. Since the rear axle of the vehicle is heavier than the front axle, the maximum displacement of the center beam caused by the crossing rear wheels is greater than that caused by the crossing front wheels. The interaction of the center beam vibrations caused by the front and rear wheels can be ignored due to the large wheelbase. Therefore, the actions of the front and rear axles in a vehicle-MBEJ coupled system can be studied separately. The maximum displacement increases from 1 st center beam to 5 th center beam, which is consistent with the change of tire load on middle beams as shown in Figure 4. The simulation result at the midpoint of center beams is shown in Table 3. It shows that the impact factor $I M$ of each center beam displacement by the crossing front wheels is greater than that of the rear wheels. The impact factors IMs of the 1st center beam displacement by the crossing front and rear wheels are the largest, which are 0.42 and 0.26 , respectively. The impact factor $I M$ of the center beam displacement is larger than the impact factor $\mu$ of the tire load.

The waveform of the dynamic tire loads acting on each center beam is approximately a sine wave, as shown in Figure 6, which verifies the assumption of tire load in $[3,5-7]$.

4.3. Parameters Affecting the Impact Factor $\mu$ of the Tire Load. In this part, the effects of the vehicle position, vehicle velocity, gap width, and spring stiffness of center beam bearing on the impact factor $\mu$ of the tire load are analyzed. When studying the effect of the vehicle position, the vehicle is considered to pass through an MBEJ from eight positions as shown in Figure 7. In positions 1, 3, 5, and 7, the left rear wheel of the vehicle passes directly above the crossbeams, and in other positions, the left rear wheel of the vehicle passes over the midpoints of the center beams span. The calculation results of the tire load impact factors $\mu$ s are shown in Figures 8-11.

Figure 8 shows that when the left rear wheel of the vehicle passes directly above the beam (in positions $1,3,5$, and 7 ), the tire load impact factors $\mu$ s of the vehicle left wheels are all reduced, but the serial number of the crossbeam where a vehicle passes has little effect on the impact 


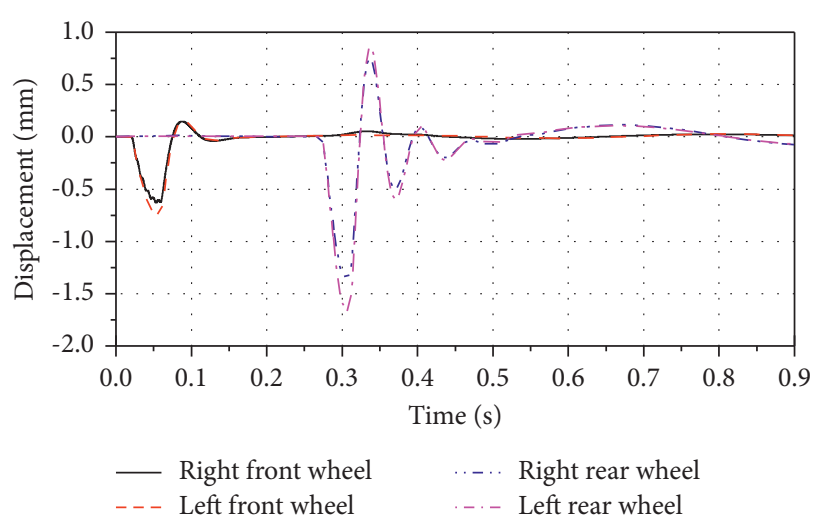

(a)

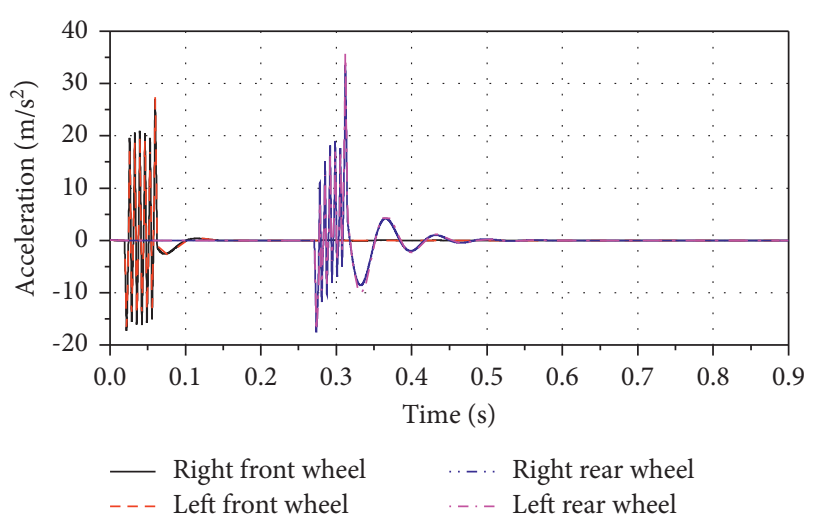

(b)

FIgURE 3: Time history of vehicle wheels: (a) displacement and (b) acceleration.

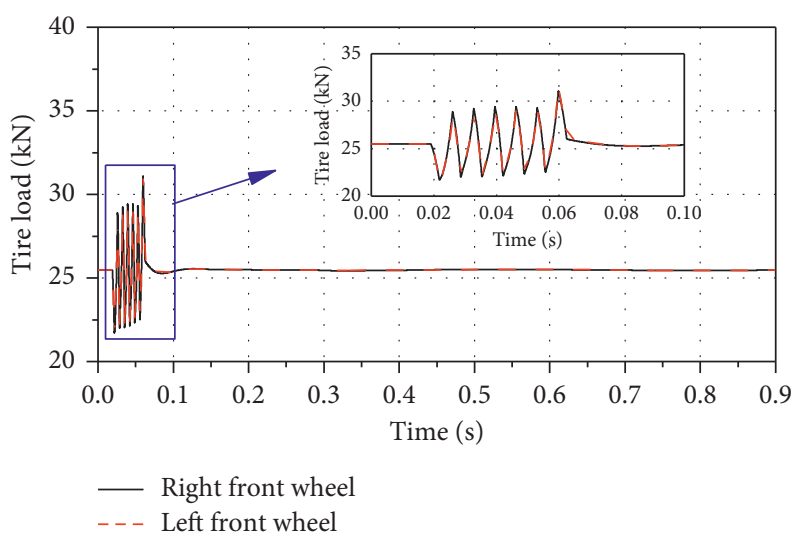

(a)

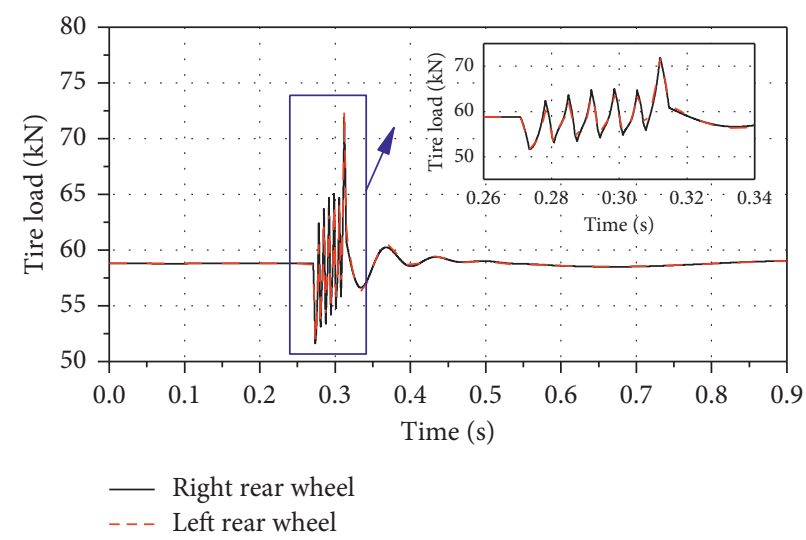

(b)

Figure 4: Dynamic tire load time history of (a) front wheel and (b) rear wheel.

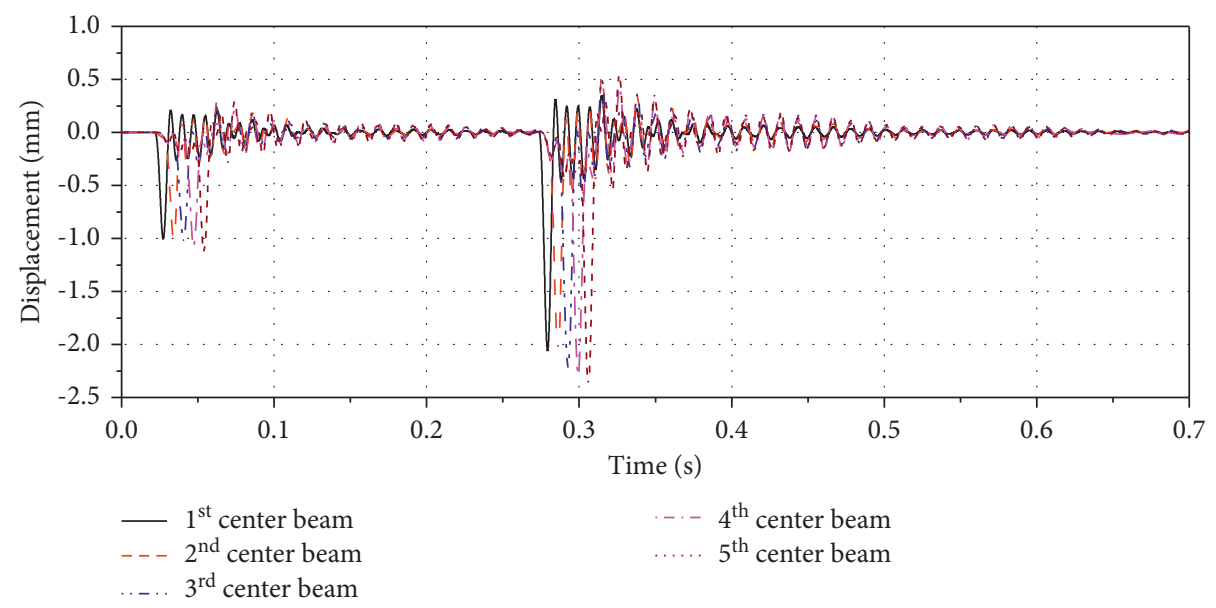

Figure 5: Vibration displacement time history at the midpoint of center beams.

factors $\mu$ s. When the vehicle drives in different positions, the maximum tire load impact factors $\mu s$ of the left front and rear wheels are 0.23 and 0.24 , respectively.
The relationship between the vehicle velocity and the impact factors $\mu$ s of the tire loads is shown in Figure 9. The tire load impact factors $\mu$ s of the vehicle left wheels increase 
TABLE 3: Simulation result at the midpoint of center beams.

\begin{tabular}{|c|c|c|c|c|c|c|}
\hline \multirow{2}{*}{ Center beam no. } & \multicolumn{3}{|c|}{ Induced by front wheel } & \multicolumn{3}{|c|}{ Induced by rear wheel } \\
\hline & $y_{\max }(\mathrm{mm})$ & $y_{\mathrm{s}}(\mathrm{mm})$ & IM & $y_{\max }(\mathrm{mm})$ & $y_{\mathrm{s}}(\mathrm{mm})$ & $\mathrm{IM}$ \\
\hline 1 & 1.01 & 0.71 & 0.42 & 2.06 & 1.64 & 0.26 \\
\hline 2 & 1.00 & 0.78 & 0.28 & 2.08 & 1.82 & 0.14 \\
\hline 3 & 1.02 & 0.84 & 0.21 & 2.22 & 1.97 & 0.13 \\
\hline 4 & 1.07 & 0.86 & 0.24 & 2.29 & 2.04 & 0.12 \\
\hline 5 & 1.13 & 0.85 & 0.33 & 2.38 & 2 & 0.19 \\
\hline
\end{tabular}

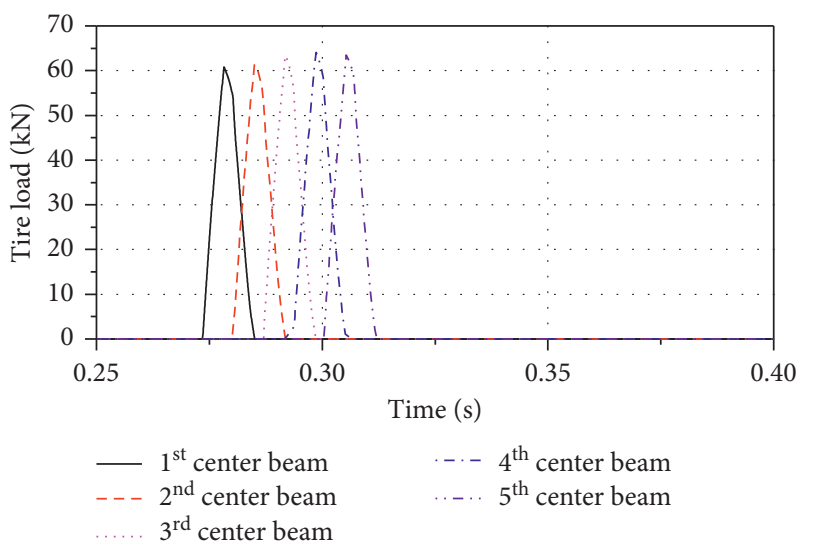

Figure 6: Tire load time history of left rear wheel on center beams.

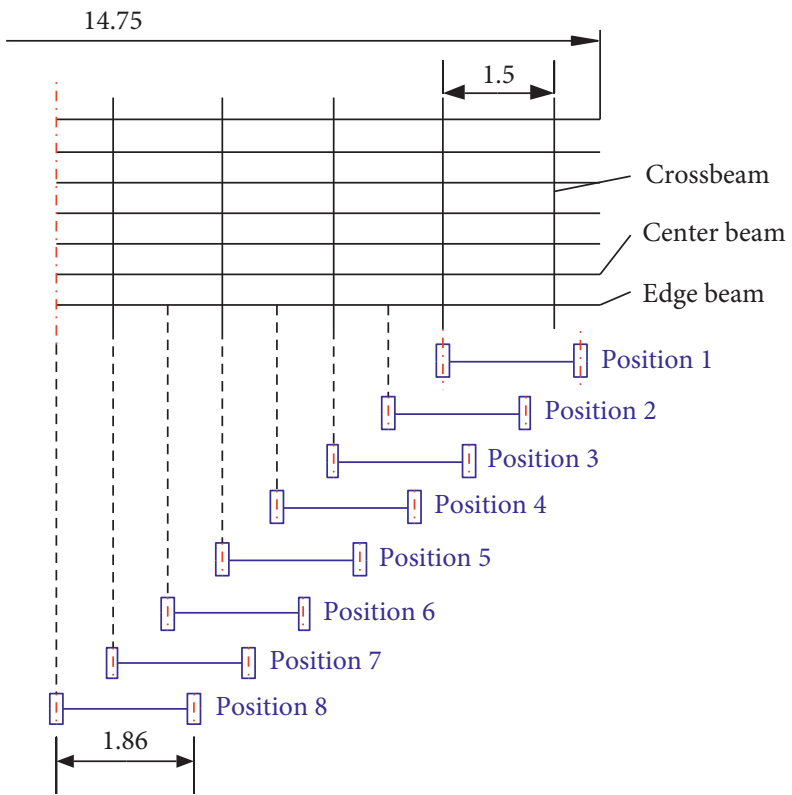

Figure 7: Positions of the vehicle crossing the MBEJ (Unit: m).

with the vehicle velocity, and the maximum tire load impact factors $\mu$ s of the left front and rear wheels are 0.33 and 0.34 , respectively, which are greater than 0.3 but less than 0.75 .

The gap width of the MBEJ will affect the tire load amplitude on a center beam and the time in which the wheel passes through a center beam. As the gap width increases, the maximum tire load acting on a center beam increases, causing the maximum displacement of the center beam to increase, which eventually leads to an increase in the impact of the tire load. Therefore, the tire load impact factors $\mu$ s of the vehicle wheels rise with the increase of gap width, as shown in Figure 10. The maximum tire load impact factors $\mu$ s of the left front and rear wheels are 0.34 , which are greater than 0.3 but less than 0.75 .

Figure 11 shows that the tire load impact factors $\mu$ s of the vehicle wheels decrease slowly with the increase of the center 


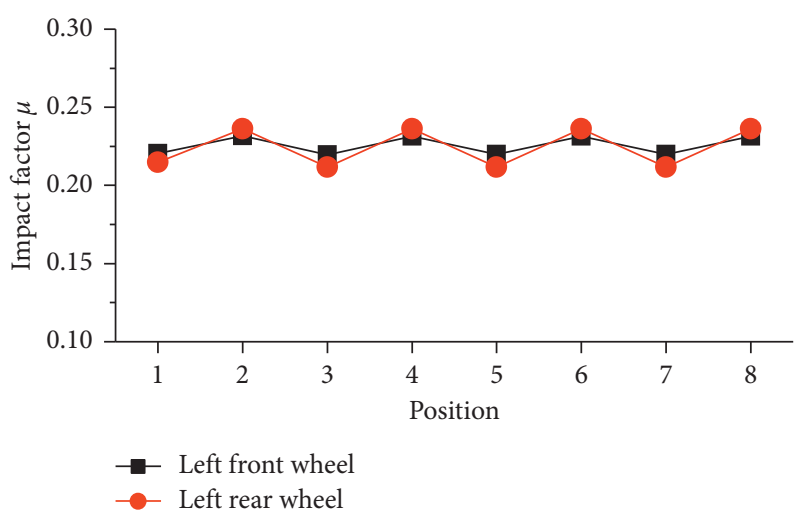

Figure 8: The effect of vehicle position on the impact factor $\mu$ of the tire loads where the vehicle velocity is $100 \mathrm{~km} / \mathrm{h}$.

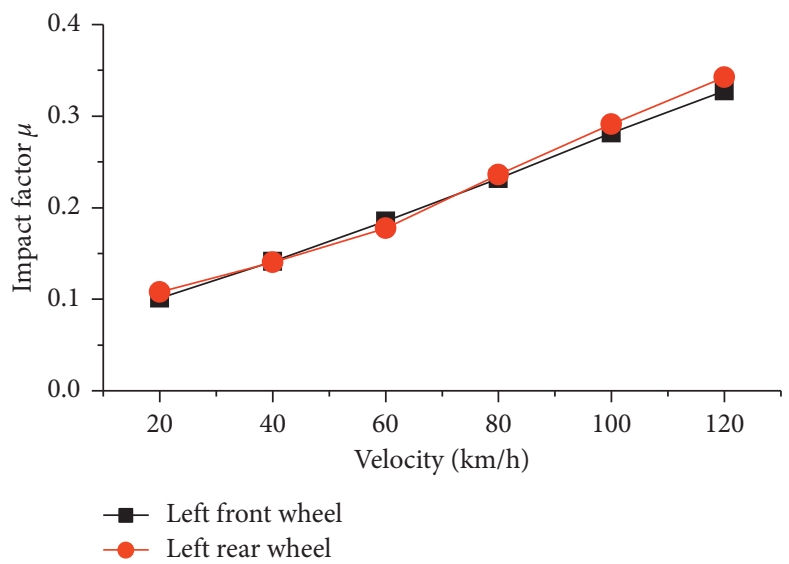

Figure 9: The effect of vehicle velocity on the impact factor $\mu$ of the tire loads.

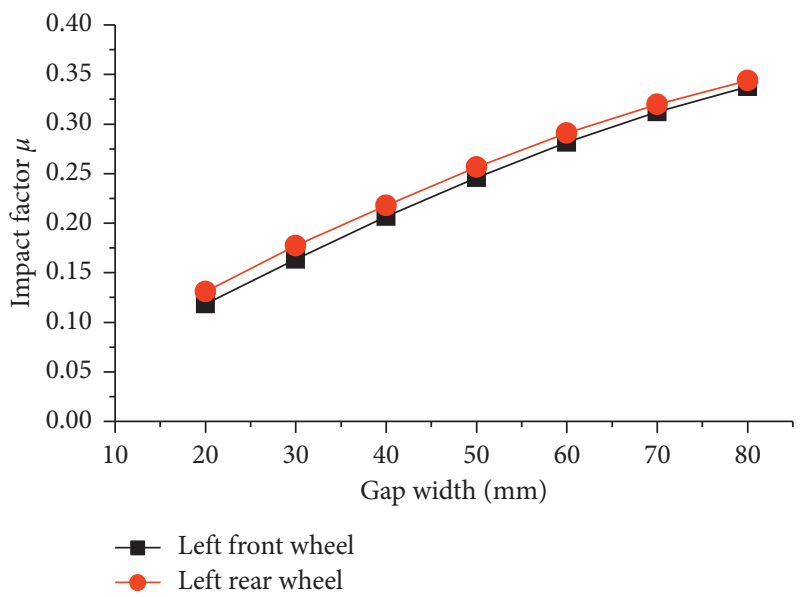

FIGURE 10: The effect of gap width on the impact factor $\mu$ of the tire loads.

beam bearing's spring stiffness. This is because as the spring stiffness of the center beam bearing increases, the maximum sinking displacement of the center beam gradually decreases, resulting in a decrease in the axle displacement. However, when the spring stiffness of the center beam bearing increases to more than $80 \mathrm{kN} / \mathrm{mm}$, this decreasing trend becomes slower. Therefore, in the design of the MBEJ, the center beam bearing's spring stiffness of $80 \mathrm{kN} / \mathrm{mm}$ can be a preferred recommended value.
4.4. Parameters Affecting the Impact Factor IM of the Canter Beam Displacement. To evaluate the effects of the vehicle position, vehicle velocity, gap width, and spring stiffness of center beam bearing on the impact factor $I M$ of the center beam displacement, a series of simulations are performed, and the calculation results are shown in Figures 12-15.

Figure 12 illustrates the effect of vehicle position on the impact factors IMs of the canter beam displacement. Similarly to impact factor $\mu$ of the tire load (see in Figure 8), the 


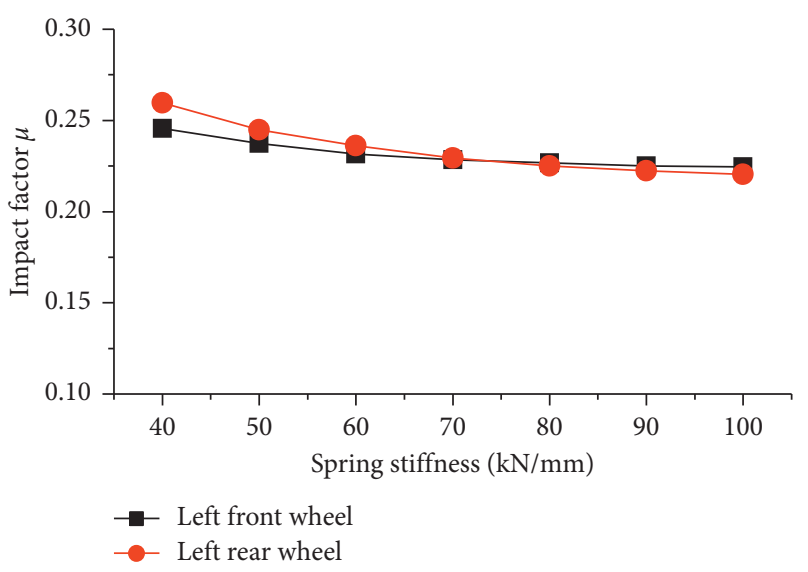

Figure 11: The effect of the center beam bearing's spring stiffness on the impact factor $\mu$ of the tire loads.

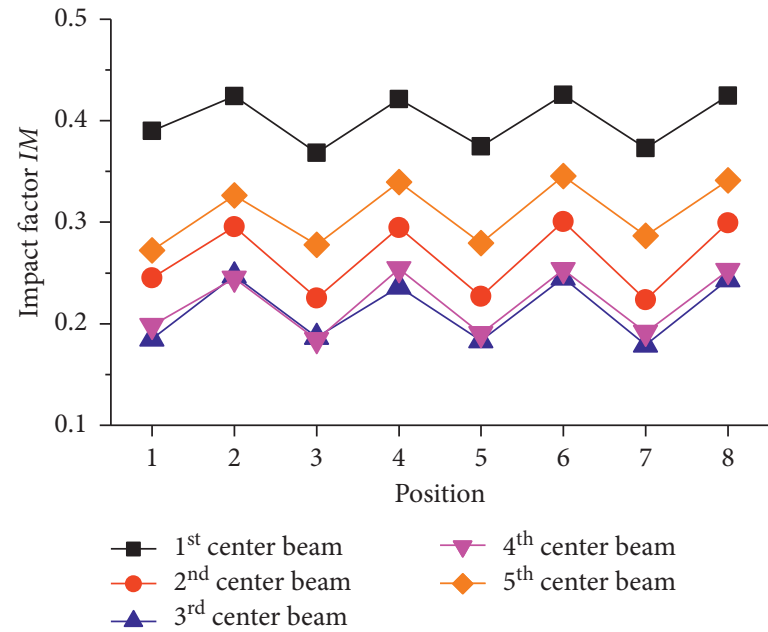

(a)

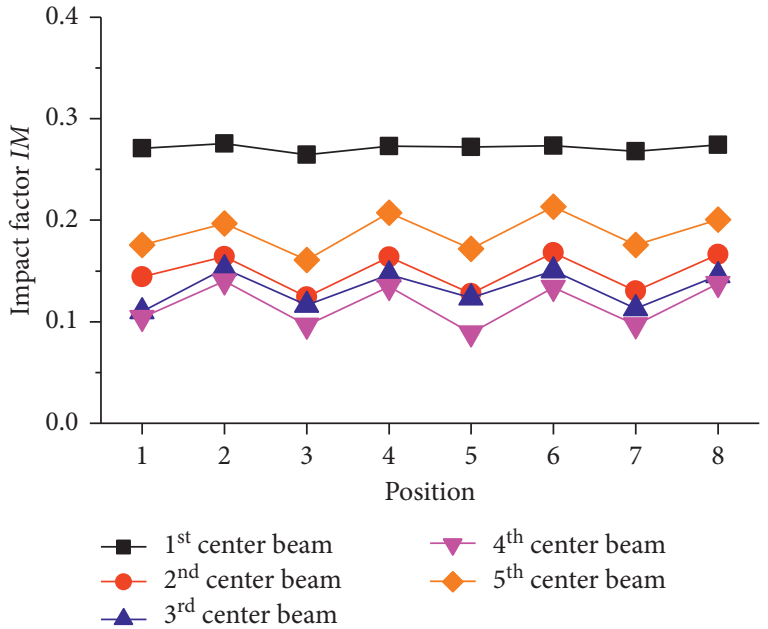

(b)

FIGURE 12: The effect of vehicle position on the impact factor $I M$ of the center beam displacement at the midpoint by (a) the crossing front wheels and (b) the crossing rear wheels.

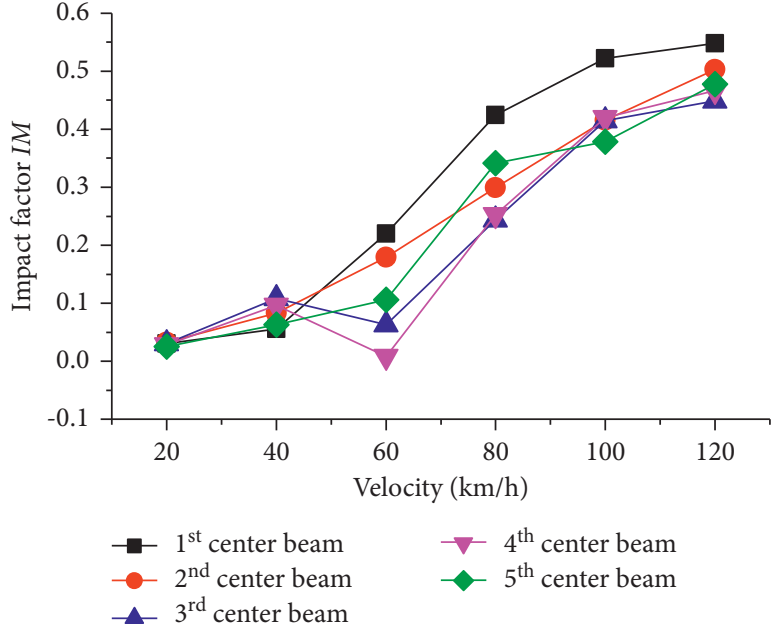

(a)

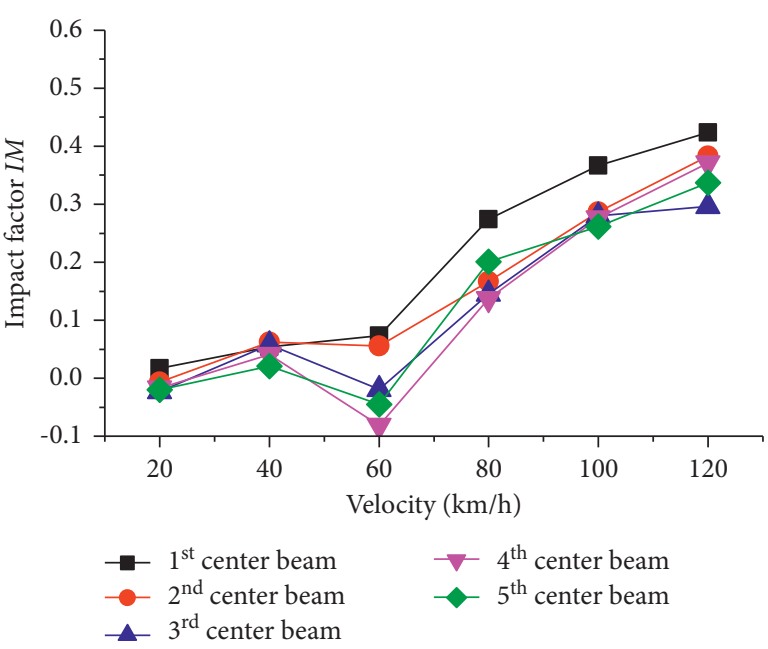

(b)

FIGURE 13: The effect of vehicle velocity on the impact factor IM of the center beam displacement at the midpoint by (a) the crossing front wheels and (b) the crossing rear wheels. 


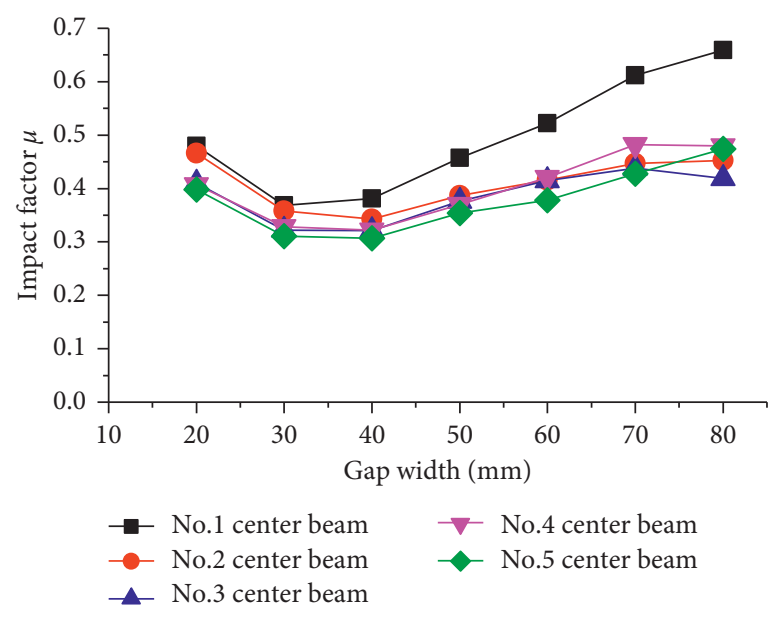

(a)

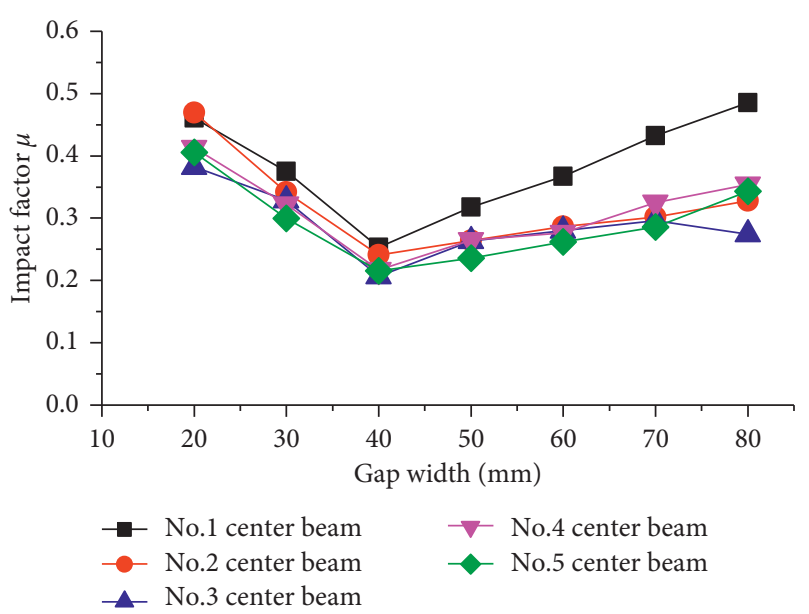

(b)

FIGURE 14: The effect of gap width on the impact factor $I M$ of the center beam displacement at the midpoint by (a) the crossing front wheels and (b) the crossing rear wheels. The vehicle velocity is $100 \mathrm{~km} / \mathrm{h}$.

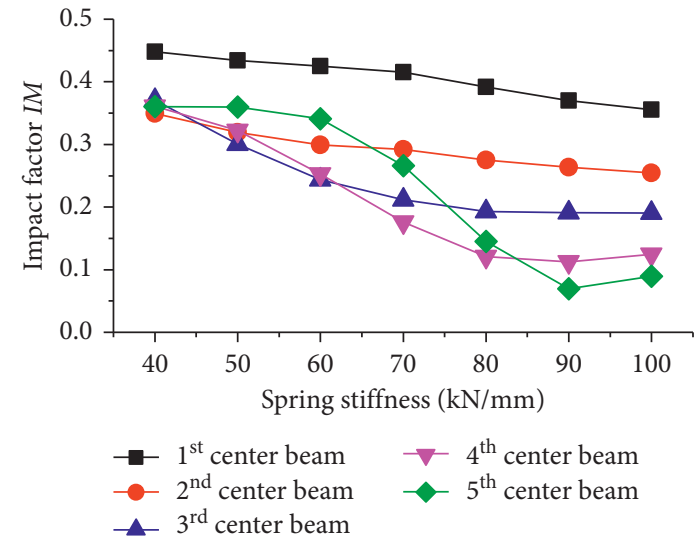

(a)

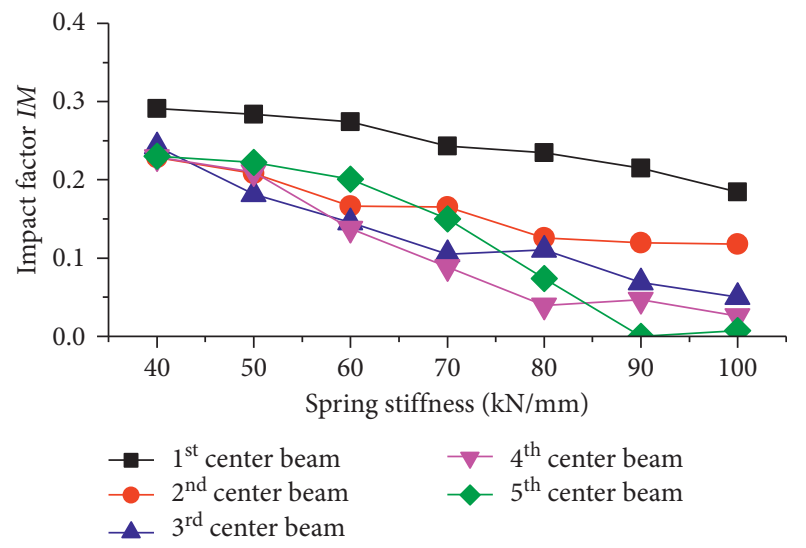

(b)

FIGURE 15: The effect of the center beam bearing's spring stiffness on the impact factor $I M$ of the center beam displacement at the midpoint by (a) the crossing front wheels and (b) the crossing rear wheels.

impact coefficients $I M s$ of the center beam displacement decrease when the left rear wheel of the vehicle passes directly above the beam (in positions 1, 3, 5, and 7), and this decreasing trend is more obvious when the front wheels pass by. The impact factors IMs are hardly affected by the serial number of the crossbeam at the position where a vehicle passes. The maximum impact factors $I M s$ of the 1st center beam displacement by the crossing front and rear wheels are 0.43 and 0.28 , respectively. The calculated impact factors IMs of the 1st center beam displacement by the crossing front wheel are greater than 0.3 but less than 0.75 .

Figure 13 shows that the impact factor $I M$ of each center beam displacement fluctuates with the increase of vehicle velocity when the vehicle velocity is less than $60 \mathrm{~km} / \mathrm{h}$. However, when the vehicle velocity is greater than $60 \mathrm{~km} / \mathrm{h}$, the impact factor $I M$ of each center beam displacement increases rapidly. The influence of vehicle velocity on the impact factor $I M$ is complex [15], which may be related to the contact time between the wheel and center beam. When the vehicle passes the MBEJ at $120 \mathrm{~km} / \mathrm{h}$, the factor $I M$ of $1 \mathrm{st}$ center beam displacement by the crossing front and rear wheels is the largest, which is 0.55 and 0.42 , respectively. Both are greater than 0.3 but less than 0.75 .

Figure 14 shows that the impact factors $I M$ s of all center beams displacement except 3rd beam first decrease and then increase with the increase of the gap width, which is due to the influence of the gap width on the contact time and tire load between the wheel and a single center beam. The impact factor $I M$ of the 3 rd center beam fluctuates with the increase of the gap width. When the gap width is $80 \mathrm{~mm}$, the impact factor $I M$ of 1st center beam displacement by the crossing front and rear wheels reaches maximums of 0.66 and 0.49 . Both are greater than 0.3 but less than 0.75 .

The effect of the center beam bearing's spring stiffness on the impact factor $I M$ of the center beam displacement is shown in Figure 15. The impact factor IM of each center beam displacement decreases with the increase of the center beam bearing's spring stiffness. However, the decreasing 
trend slows down when the spring stiffness of the center beam bearing increases to greater than $80 \mathrm{kN} / \mathrm{mm}$. Similar results were obtained by Li et al. [10].

\section{Conclusions}

In this paper, a dynamic mathematical model of a vehicleexpansion joint coupled system is established with a flexible roller tire model. The numerical simulations are carried out with different system parameters to study the dynamic response of the coupled system. Two impact factors $\mu$ and $I M$ are defined to evaluate the dynamic impact effects of the tire load and the center beam displacement. The following conclusions can be drawn from the studies:

(1) For the 2-axle vehicle, the interaction between the front and rear wheels can be ignored when the vehicle passes through the MBEJ, so they can be studied separately. The impact factor $\mu$ increases with the vehicle velocity and the gap width. This implies that limiting the vehicle velocity contributes to improving the vehicle safety, especially in winter with a big gap.

(2) For the bridge expansion joint, the tire loads on the edge beam and the concrete at the end of the bridge deck are the largest. The strength of the connection between the MBEJ and the bridge deck should be considered during the design of an MBEJ. The impact effects of the vehicle and the expansion joint can be improved when the vehicle wheel passes directly above the crossbeam. Therefore, the position design of the crossbeams should take into account the distribution of tire road imprints during the design of an MBEJ. However, the relationships of the impact factor $I M$ with the speed and the gap width are not monotonous functions. When the vehicle speed is $60 \mathrm{~km} / \mathrm{h}$ or the gap width is $40 \mathrm{~mm}$, the impact factor $I M$ will decrease suddenly. The increase of the center beam bearing's spring stiffness can reduce the impact of both vehicle and expansion joint.

(3) The calculated impact factor $I M$ is greater than the impact factor $\mu$. Therefore, a distinction should be made when using impact factors for static calculations. The maximum impact factor $\mu$ can reach 0.34 , and the maximum impact factor $I M$ can reach 0.58 . Both impact factors may exceed the values specified by the Chinese or European bridge codes.

The simulation results will provide useful guidance for the design and maintenance of expansion joint and bridge. However, the interaction between the parameters and the influence of different types of vehicles on the vehicle-expansion joint coupled system have yet to be achieved. These issues remain potential topics of future work.

\section{Data Availability}

The data used to support the findings of this study are available from the corresponding author upon request.

\section{Conflicts of Interest}

The authors declare that they have no conflicts of interest.

\section{Acknowledgments}

This research was supported by the National Science Foundation for Distinguished Young Scholars of China (Grant no. 51805166).

\section{References}

[1] J. Marques Lima and J. de Brito, "Inspection survey of 150 expansion joints in road bridges," Engineering Structures, vol. 31 , no. 5, pp. 1077-1084, 2009.

[2] J. M. Lima and J. de Brito, "Management system for expansion joints of road bridges," Structure and Infrastructure Engineering, vol. 6, no. 6, pp. 703-714, 2010.

[3] M. Y. Zhu, Y. Ding, and Z. Y. Li, "Strength analysis and optimization of bridge expansion joint based on computer simulation," in Proceedings of the International Conference on Computers and Industrial Engineering, vol. 2019, Beijing, China, October 2019.

[4] Z. Sun and Y. Zhang, "Failure mechanism of expansion joints in a suspension bridge," Journal of Bridge Engineering, vol. 21, no. 10, 13 pages, Article ID 05016005, 2016.

[5] G. Li, W. Han, X. Chen, T. Guo, Q. Xie, and Y. Yuan, "Wear evaluation on slide bearings in expansion joints based on cumulative displacement for long-span suspension bridge under monitored traffic flow," Journal of Performance of Constructed Facilities, vol. 34, no. 1, pp. 723-738, 2020.

[6] G. N. Stamatopoulos, "Fatigue life of the bolted yoke connection in single support beam (SSB) modular bridge expansion joints," International Journal of Steel Structures, vol. 17, no. 2, pp. 723-738, 2017.

[7] Z. F. shun, S. H. Wang, and H. Wu, "Coupling dynamic research of the large displacement bridge expansion joints," Highway Engineer, vol. 39, no. 2, pp. 59-62, 2014.

[8] M. J. M. M. Steenbergen, "Dynamic response of expansion joints to traffic loading," Engineering Structures, vol. 26, no. 12, pp. 1677-1690, 2004.

[9] E. J. Ancich, G. J. Chirgwin, and S. C. Brown, "Dynamic anomalies in a modular bridge expansion joint," Journal of Bridge Engineering, vol. 11, no. 5, pp. 541-554, 2006.

[10] B. Li, S. Wang, X. Wu, and B. Wang, "Dynamic response of continuous beams with discrete viscoelastic supports under sinusoidal loading," International Journal of Mechanical Sciences, vol. 86, pp. 76-82, 2014.

[11] Q. M. Yan, S. H. Wang, and G. Yang, "Research of vertical dynamic response of the large displacement bridge expansion joint," Machinery Design and Manufacture, vol. 7, pp. 41-43, 2013.

[12] X. Xie, D. Y. Wu, J. F. Wang, S. Q. Zhang, and Y. J. Zhou, "Dynamical behavior of steel box girder bridges due to vehicle-induced vibration at expansion joint," Journal of Zhejiang University, vol. 43, no. 10, pp. 1923-1930, 2009.

[13] Y. P. Wu, D. Y. Wu, X. Xie, and H. Zhang, "Response and vibration control of steel box-girder bridge when vehicles passing through the expansion joint," Noise and Vibration Control, no. 2, pp. 95-100, 2013.

[14] Z. Sun and Y. F. Zhang, "Vehicle-induced dynamic response of expansion joints in long span bridges," Applied Mechanics and Materials, vol. 584-586, pp. 2117-2120, 2014. 
[15] L. Deng, W. Yan, and Q. Zhu, "Vehicle impact on the deck slab of concrete box-girder bridges due to damaged expansion," Journal of Bridge Engineering, vol. 21, no. 2, 13 pages, Article ID 06015006, 2016.

[16] R. Friedl and I. Mangerig, "Dynamic amplification of bridgeexpansion-joints considering roughness induced vehicle vibrations," Procedia Engineering, vol. 199, pp. 2651-2656, 2017.

[17] I. Mangerig and R. Friedl, "Dynamic interaction between vehicles and bridge expansion joints," in Proceedings of the International Conference on Structural Dynamic, vol. 2014, pp. 1153-1160, Porto, Portugal, January 2014.

[18] Y. Ding, X. Xie, G. D. Qu, and J. Y. Huang, "Analysis of dynamic load of vehicle bumping at bridge-head using distributed spring-damper element," China Civil Engineering Journal, vol. 45, no. 12, pp. 127-135, 2012.

[19] Y. Ding, W. Zhang, and F. T. K. Au, "Effect of dynamic impact at modular bridge expansion joints on bridge design," Engineering Structures, vol. 127, pp. 645-662, 2016.

[20] L. Zhang, B. Li, and S. H. Wang, "Numerical simulation method for vertical vibration of heavy vehicle-expansion joint coupled system," Journal of Southwest Jiaotong University, 2021.

[21] S. H. Li and S. P. Yang, "Dynamical interaction between heavy vehicle and road pavement," Journal of Vibration and Shock, vol. 28, no. 6, pp. 155-158, 2009.

[22] K. H. Guo, Q. Liu, and G. F. Ding, “Analysis of tire enveloping properties and its application in modelling of vehicle vibration systems," Automotive Engineering, vol. 21, no. 2, pp. 65-71, 1999.

[23] S. Yang, S. Li, and Y. Lu, "Dynamics of vehicle-pavement coupled system based on a revised flexible roller contact tire model," Science in China - Series E: Technological Sciences, vol. 52, no. 3, pp. 721-730, 2009.

[24] K. H. Gong, Q. Liu, and G. F. Ding, "Influences of loading and inflation pressure on tire enveloping properties," Transactions of the Chinese Society of Agricultural Engineering, vol. 14, no. 3, pp. 58-60, 1998.

[25] Z. B. Cui, "Theoretical and experimental research on controllable design for ground performance of radial tire," Doctoral Dissertation, Harbin Institute of Technology, Harbin, China, 2016.

[26] W.-M. Zhai, "Two simple fast integration methods for largescale dynamic problems in engineering," International Journal for Numerical Methods in Engineering, vol. 39, no. 24, pp. 4199-4214, 1996.

[27] Ministry of Communications of P R China, General Specification for Design of Highway Bridges and Culverts (JTG D602015), Beijing, China, 2015.

[28] British Standards Institution, Eurocode 1: Actions on Structures-Part 2: Traffic Loads on Bridges (BS EN 1991-2), BSI, UK, 2003.

[29] American Association of State Highway and Transportation Officials (Aashto), LRFD Bridge Design specifiations, AASHTO, Washington, DC, USA, 5th edition, 2010. 